\title{
Community Opinions about African Wild Dog Conservation and Relocations near the Serengeti National Park, Tanzania
}

\author{
Emmanuel H Masenga ${ }^{1,2}$, Richard D Lyamuya ${ }^{1,2}$, Mjingo E Eblate ${ }^{1}$, Robert D Fyumagwa ${ }^{1}$ \& Eivin Røskaft ${ }^{2}$ \\ ${ }^{1}$ Tanzania Wildlife Research Institute (TAWIRI), Serengeti Wildlife Research Centre (SWRC), P. O. Box 661, \\ Arusha, Tanzania. \\ ${ }^{2}$ Department of Biology, Norwegian University of Science and Technology (NTNU), Realfagbygget, NO-7491 \\ Trondheim, Norway \\ Correspondence: Eivin Røskaft, Department of Biology, Norwegian University of Science and Technology \\ (NTNU), Realfagbygget, NO-7491 Trondheim, Norway. E-mail: eivin.roskaft@ntnu.no
}

Received: September 15, 2016

Accepted: October 5, $2016 \quad$ Online Published: October 24, 2016

doi: 10.5539/enrr.v6n4p51

URL: http://dx.doi.org/10.5539/enrr.v6n4p51

\begin{abstract}
Conservation of the African wild dog (Lycaon pictus) in human-dominated landscapes faces many challenges. Understanding human opinions of wild dog conservation is important to inform management decisions. Questionnaire surveys, including both open and closed-ended questions, were administered by researchers through face-to-face interviews of 297 respondents in the eastern part of the Serengeti ecosystem between January and February 2012. Our results indicated that most local people believed that wild dogs were extinct in the Serengeti ecosystem. According to the local people, wild dogs should have a high conservation priority. Moreover, tribe and gender are important demographic variables that explain the negative or positive perceptions of-attempts to relocate wild dogs from the Loliondo Game Controlled Area to the Serengeti National Park (SNP). We conclude that future conservation interventions should focus on the interface between community knowledge and modern conservation science.
\end{abstract}

Keywords: conservation, African wild dogs, knowledge, tribe, gender, translocation

\section{Introduction}

Human population increase, habitat loss and urbanization have accelerated the contact between humans and wildlife globally (Howe, Obbard, Black, \& Wall, 2010; Lagendijk \& Gusset, 2008; Packer et al., 2013; Pan et al., 2016; Treves \& Karanth, 2003; Valeix, Hemson, Loveridge, Mills, \& Macdonald, 2012; Woodroffe, 2000; Zimmermann et al., 2010). Conflict with carnivores, including African wild dogs (Lycaon pictus), cheetahs (Acinonyx jubatus), lions (Panthera leo), brown bears (Ursus arctos), hyaenas (Crocuta crocuta) and wolves (Canis lupus), are particularly are particularly difficult to mitigate (Ghosal, Skogen, \& Krishnan, 2015; Howe et al., 2010; Johansson \& Frank, 2016; Trouwborst, 2015). Interactions between humans and carnivores might have fatal consequences on both sides (Løe \& Røskaft, 2004; Packer et al., 2013). Some studies have reported that humans accept co-existence when carnivores do not cause harm to human property or well-being (Dickman, Macdonald, \& Macdonald, 2011 ; Lindsey et al., 2013; Woodroffe, Lindsey, Romanach, Stein, \& ole Ranah, 2005), although the benefit of sharing land can never be equal for humans and carnivores. In the Loliondo Game Controlled Area (LGCA) in northern Tanzania, African wild dogs are the most common predator co-existing with humans. Their survival, however, requires a multi-stakeholder conservation approach (Masenga et al., 2013).

In many parts of the world, human behaviour affects the presence and distribution of carnivore species (Karlsson \& Sjöström, 2011; Treves \& Karanth, 2003; Trouwborst, 2015). Human behaviour differs, however, between individuals with respect to resource use, cultural and social needs (Parker, Whittington-Jones, Bernard, \& Davies-Mostert, 2014; Schuette, Creel, \& Christianson, 2013; Zimmermann et al., 2010). To acquire an understanding of human behaviour towards carnivore conservation, various social demographic factors have been studied (Lindsey, Du Toit, \& Mills, 2005; Lyamuya, Masenga, Fyumagwa, \& Røskaft, 2014; Lyamuya et al., 2014; Røskaft, Bjerke, Kaltenborn, Linnell, \& Andersen, 2003; Røskaft, Händel, Bjerke, \& Kaltenborn, 2007; Stein, Fuller, Damery, Sievert, \& Marker, 2010). In Europe, for example, some studies have shown that people fear wolves and brown bears (Howe et al., 2010; Johansson \& Frank, 2016; Røskaft et al., 2003; 
Zimmermann et al., 2010). On the other hand, no study has been conducted to allow local people to provide their general opinions about the presence of wild dogs on their land and relocation in the Serengeti ecosystem.

Many challenges have been documented when conserving wild dogs in human-dominated landscapes, as they attack livestock and range widely (Lyamuya et al., 2014; Weise, Stratford, \& van Vuuren, 2014; Woodroffe, 2011; Woodroffe et al., 2005). However, priority conservation is often considered to be highly important in areas where wild dogs are found. To solve many of these challenges, translocation of packs or individual dogs has been suggested and has been successful in small reserves in South Africa (Davies-Mostert, Mills, \& Macdonald, 2015; Gusset et al., 2008).

Wild dogs are in need of a high conservation priority due to their alarming and ongoing decline (Woodroffe 2011). In Tanzania, wildlife conservation authorities have identified important areas to conserve the species in order to ensure future viable populations, as the country has one of the largest free-roaming wild dog populations in the world (TAWIRI, 2009). The LGCA contains a sizeable population that is suffering from persecution (Masenga, 2011; Masenga et al., 2013). Little information is available to provide a clear understanding of the nature of the co-existence between wild dogs and humans. Humans may develop general opinions about any situation pertaining to them (Inskip, Carter, Riley, Roberts, \& MacMillan, 2016; Linnell, Swenson, \& Anderson, 2001; Løe \& Røskaft, 2004). Based on this background, we tested the general hypothesis that local awareness of wild dogs influences human perceptions regarding the conservation status and translocation of this endangered species in the Serengeti ecosystem. To test this hypothesis, we focused on the following predictions:

1) Local knowledge of the International Union for Conservation of Nature (IUCN) categories and of the conservation status of wild dogs differs between genders and tribes, with men and the Maasai tribe being more knowledgeable than females and the Sonjo tribe.

2) Priorities for conserving wild dogs differ between the two tribes: the Maasai tribe regards wild dogs as a more important species than the Sonjo tribe.

3) Local people support the translocation of wild dogs from the LGCA to the SNP.

Suggestions from local inhabitants may provide information about the actual situation facing wild animal species, such as wild dogs. Therefore, their opinions are important to consider when assessing and predicting the future conservation of the species in an area.

\section{Methods}

\subsection{Study Area}

This study was conducted in the LGCA covering six villages, including: Ololosokwan, Soitsambu, Malambo, Piyaya, Samunge and Digodigo (Figure 1). This area is part of the larger Serengeti ecosystem and has a significant presence of wildlife, Maasai pastoralists and Sonjo agro-pastoralists (Homewood et al., 2001). Land-use conflicts within this area have occurred between the government and local communities in terms of both wildlife and livestock utilization (Nelson \& Makko, 2005). The human population of the Ngorongoro district is approximately 175,000 individuals, consisting of 83,000 and 92,000 males and females, respectively (NBS, 2012). The growth rate is rapid, at $2.7 \%$ (NBS, 2012), and the human population density is high in the Loliondo and Sale divisions. The area receives bimodal rainfall ranging between $400 \mathrm{~mm}$ and $600 \mathrm{~mm}$, with an annual temperature of $20.8^{\circ} \mathrm{C}$, which varies by $3^{\circ}-5^{\circ} \mathrm{C}$ daily (Homewood et al., 2001; Tumbo, Mutabazi, Kimambo, \& Rwehumbiza, 2011). The vegetation in the area varies from short grass plains to forests on higher hills. Acacia spp. form in open woodlands, and Fagaropsis anglolensis, Olea welwitschii and Juniperus procera are found in forest areas (Homewood et al., 2001). African wild dogs, cheetahs, lions, leopards, hyenas, and several species of small carnivores are regularly found in the area. The occurrence of wild dogs is more evident during the season when wildebeest (Connochaetes taurinus) migrate through the area.

\subsection{Sampling and Data Collection}

Respondents for interviews were randomly selected from the village or ward register books. In our case, a village is considered to be an area with less than 10,000 people (NBS, 2012). Villages were selected purposively due to the occurrence of African wild dogs in the area (Masenga, 2011). We selected 50 respondents from each village to represent our sample by generating random numbers. Thus, we ensured maximization of knowledge of the species while testing the opinions of the local people. Data were collected from questionnaires provided to 300 respondents between January and February 2012. The researchers administered both open and closed-ended questions to 297 respondents through face-to-face interviews. Though, three respondents were unable to respond to the questionnaires. 


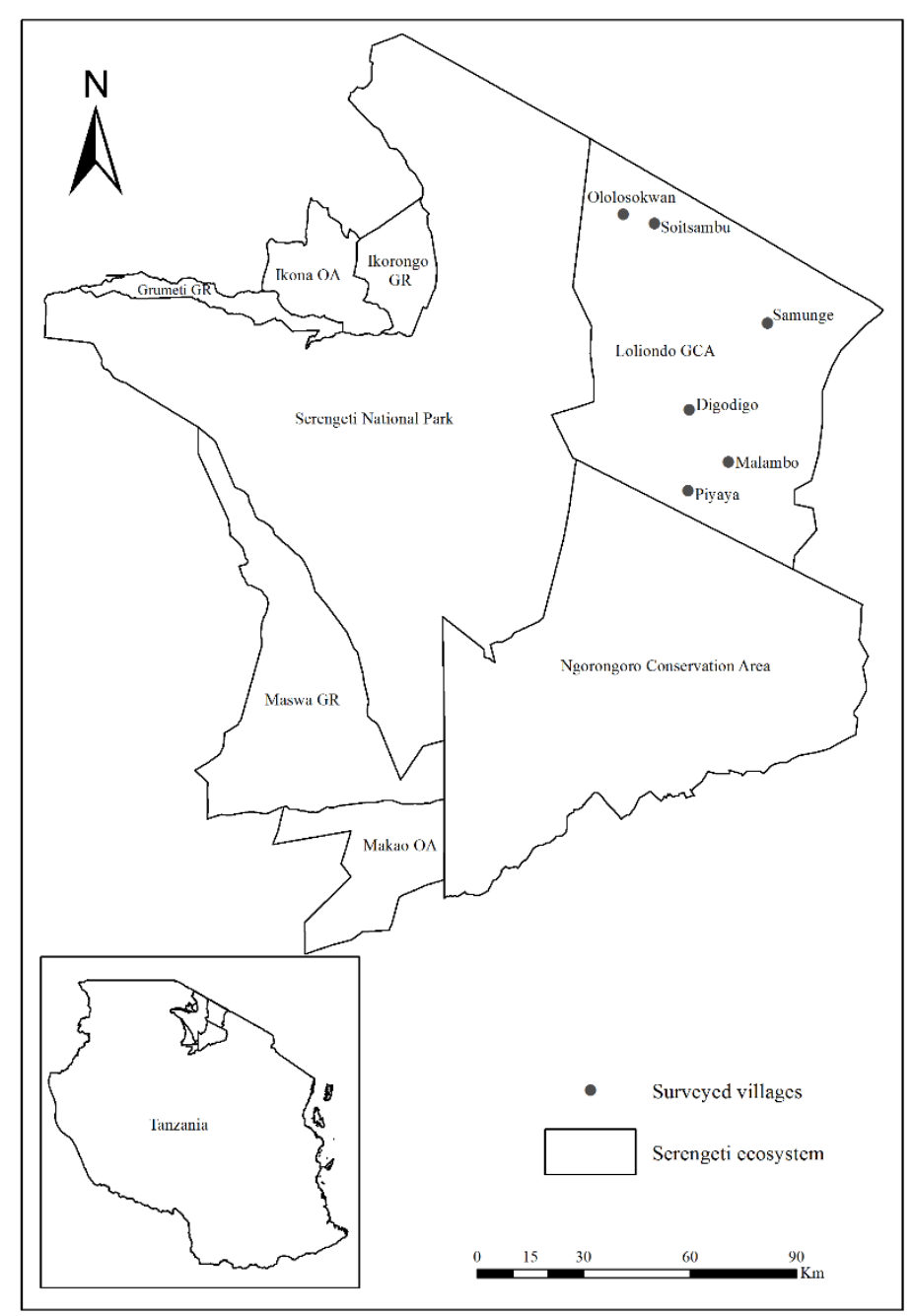

Figure 1. A map of the Serengeti ecosystem showing the study villages within the Loliondo Game Controlled Area

\subsection{The Questionnaire Structure and Codes}

Demographic variables were collected, grouped and coded as follows: gender was coded as 1 (male) and 2 (female); ages were grouped as "youth" (18 - 35 years), "adults" (36 - 45 years) and "elders" ( $>46$ years); tribes were coded 1 (Maasai) and 2 (Sonjo); education level was coded 1 (no education), 2 (primary school) and 3 (secondary school and above); and occupation was coded 1 (pastoralist) and 2 (farmer and agro-pastoralist). Furthermore, other variables were coded and addressed by the following questions: i) The question on local knowledge of wild dogs (IUCN categories) was coded as 1 (extinct), 2 (critically endangered), 3 (endangered), 4 (vulnerable) and 5 (lower risk); ii) priorities of conserving wild dogs were coded as 1 (high), 2 (medium) and 3 (low); iii) perception of capture and release of wild dogs were coded 1 (positive), 2 (neutral) and 3 (negative).

\subsection{Data Analysis}

All analyses were conducted using Statistical Package for Social Science (SPSS) version 21. Most data were categorical; therefore, we used non-parametric tests, e.g., chi-square tests. However, linear regression models were used to test the general opinions of respondents with respect to different response questions. All statistical tests were two-tailed, with the significance level set at $\mathrm{p} \leq 0.05$ (Andy, 2009).

\section{Results}

\subsection{Community Conservation Perceptions Under the IUCN Categories}

Males and females had different perceptions regarding wild dog conservation under the IUCN categories. Significantly more females than males considered wild dogs to be an extinct species. Males, on the other hand, 
more frequently reported that wild dogs belong to the lower risk categories $\left(\chi^{2}=12.46, \mathrm{df}=4, \mathrm{P}=0.014\right.$; Table 1$)$. No significant differences were found in relation to age $(\mathrm{P}=0.58)$, occupation $(\mathrm{P}=0.40)$ or education level $(\mathrm{P}=$ 1.11). However, the two tribes expressed different views with a significantly higher proportion of the Sonjo people considering wild dogs to be an extinct species $\left(\chi^{2}=16.56, \mathrm{df}=4, \mathrm{P}=0.002\right.$; Table 1$)$. A linear regression analysis with conservation perception as the dependent variable and gender and tribe as independent variables was significant $\left(\mathrm{F}=5.607, \mathrm{df}=2\right.$ and $\left.294, \mathrm{P}=0.004, \mathrm{r}^{2}=0.030\right)$. However, only gender $(\mathrm{t}=-3.112, \mathrm{P}=0.002)$ was a significant contributor in explaining this variation.

Table 1. Local perception of the conservation status (IUCN categories) of African wild dogs in relation to gender and tribe in the Loliondo Game Controlled Area $(\mathrm{N}=297)$.

\begin{tabular}{llllll}
\hline IUCN & \multicolumn{3}{l}{ Conservation Perception } & & \\
\hline Conservation status & Gender & & Tribe & & \\
& Males & Females & Sonjo & Maasai & Total \\
& $n \%$ & $n \%$ & $n \%$ & $n \%$ & $n \%$ \\
Extinct & $48(28.1)$ & $53(42.0)$ & $42(42.0)$ & $59(29.9)$ & $101(34.0)$ \\
Critically endangered & $13(7.6)$ & $17(13.5)$ & $8(8.0)$ & $22(11.2)$ & $30(10.1)$ \\
Endangered & $36(21.1)$ & $22(17.5)$ & $20(20.0)$ & $38(19.3)$ & $58(19.5)$ \\
Vulnerable & $38(22.2)$ & $17(13.5)$ & $7(7.0)$ & $48(24.4)$ & $55(18.5)$ \\
Lower risk & $36(21.0)$ & $17(13.5)$ & $23(23.0)$ & $30(15.2)$ & $53(17.9)$ \\
Total & $171(100)$ & $126(100)$ & $100(100)$ & $197(100)$ & $297(100)$ \\
\hline
\end{tabular}

\subsection{Conservation Priorities}

In general, most respondents considered the conservation priority of wild dogs to be high. However, the response by tribe differed, as significantly more Maasai than Sonjo people regarded the conservation priority of wild dogs as low $\left(\chi^{2}=8.04, \mathrm{df}=2, \mathrm{P}=0.018\right.$; Table 2$)$. Furthermore, the educated respondents regarded the conservation priority as high, while uneducated respondents considered the conservation status to be low or medium $\left(\chi^{2}=16.81\right.$, $\mathrm{df}=4, \mathrm{P}=0.002$; Table 2). No significant differences were found in relation to sex $(\mathrm{P}=0.42)$, occupation ( $\mathrm{P}=$ $0.29)$ or age $(\mathrm{P}=0.20)$. A linear regression analysis with conservation priority as the dependent variable and tribe and education level as independent variables was statistically significant $\left(\mathrm{F}=6.975, \mathrm{df}=2\right.$ and, 294, $\mathrm{P}<0.001, \mathrm{r}^{2}=$ 0.039). Only education level $(\mathrm{t}=-3.428, \mathrm{P}=0.001)$ was independently significant in explaining this variation.

Table 2. Perceptions of conservation priorities of African wild dogs in relation to tribe and education level

\begin{tabular}{|c|c|c|c|c|c|c|}
\hline \multirow[b]{2}{*}{ Priorities } & \multicolumn{2}{|l|}{ Tribe } & \multicolumn{3}{|c|}{ Level of education } & \multirow[b]{2}{*}{$\begin{array}{l}\text { Total } \\
n \% \\
\end{array}$} \\
\hline & $\begin{array}{l}\text { Sonjo } \\
n \%\end{array}$ & $\begin{array}{l}\text { Maasai } \\
n \%\end{array}$ & $\begin{array}{l}\text { No education } \\
n \%\end{array}$ & $\begin{array}{l}\text { Primary education } \\
n \%\end{array}$ & $\begin{array}{l}\text { Secondary education and above } \\
n \%\end{array}$ & \\
\hline High & $65(65.0)$ & $124(63.0)$ & $8(30.8)$ & $120(63.8)$ & $61(73.5)$ & $189(63.6)$ \\
\hline Medium & $29(29.0)$ & $40(20.0)$ & $10(38.4)$ & $45(23.9)$ & $14(16.9)$ & $69(23.3)$ \\
\hline Low & $6(6.0)$ & $33(17.0)$ & $8(30.8)$ & $23(12.3)$ & $8(9.6)$ & $39(13.1)$ \\
\hline Total & $100(100)$ & $197(100)$ & $26(100)$ & $188(100)$ & $83(100)$ & $297(100)$ \\
\hline
\end{tabular}

\subsection{Perceptions on Capturing and Relocating Wild Dogs}

The Maasai tribe respondents were more negative towards capturing wild dogs than the Sonjo people $\left(\chi^{2}=6.89\right.$, $\mathrm{df}=2, \mathrm{P}=0.032$; Table 3$)$. No significant differences were found in relation to sex $(\mathrm{P}=0.592)$, occupation $(\mathrm{P}=$ $0.277)$, age $(\mathrm{P}=0.519)$ or education level $(\mathrm{P}=0.519)$.

Females were significantly more positive than males towards the relocation of wild dogs into SNP $\left(\chi^{2}=6.52\right.$, df $=$ $2, \mathrm{P}=0.038$; Table 3). No significant differences in this respect were found in relation to occupation $(\mathrm{P}=0.277)$, age $(\mathrm{P}=0.519)$ or education level $(\mathrm{P}=0.260)$. In contrast to capture, the Maasai people were more positive towards releasing wild dogs into SNP than the Sonjo people $\left(\chi^{2}=19.46, \mathrm{df}=2, \mathrm{P}<0.001\right.$; Table 3$)$. A linear regression analysis with release perception as the dependent variable and gender and tribe as independent variables was statistically significant $\left(\mathrm{F}=8.073, \mathrm{df}=2\right.$ and, 294, $\left.\mathrm{P}<0.001, \mathrm{r}^{2}=0.046\right)$. Both tribe $(\mathrm{t}=-3.483, \mathrm{P}<0.001)$ and gender $(\mathrm{t}=-2.602, \mathrm{P}=0.010)$ were independently significant in explaining this variation. 
Table 3. Perceptions of the local people regarding capturing (in LGCA) or releasing (in SNP) African wild dogs in relation to tribe and gender

\begin{tabular}{lllllllll}
\hline Perceptions & \multicolumn{3}{c}{ Capturing } & \multicolumn{5}{c}{ Releasing } \\
\cline { 2 - 9 } & \multicolumn{3}{c}{ Tribe } & \multicolumn{3}{c}{ Gender } & \multicolumn{3}{c}{ Tribe } \\
& Sonjo & Maasai & Total & Male & Female & Sonjo & Maasai & Total \\
& $n \%$ & $n \%$ & $n \%$ & $n \%$ & $n \%$ & $n \%$ & $n \%$ & $n \%$ \\
\hline Positive & $43(43.0)$ & $56(28.0)$ & $99(33.0)$ & $78(46.0)$ & $75(60.0)$ & $44(44.0)$ & $109(55.0)$ & $153(52.0)$ \\
Neutral & $9(9.0)$ & $29(15.0)$ & $38(13.0)$ & $23(13.0)$ & $9(7.0)$ & $3(3.0)$ & $29(15.0)$ & $32(10.0)$ \\
Negative & $48(48.0)$ & $112(57.0)$ & $160(54.0)$ & $70(41.0)$ & $42(33.0)$ & $53(53.0)$ & $59(30.0)$ & $112(38.0)$ \\
Total & $100(100.0)$ & $197(100.0)$ & $297(100.0)$ & $171(100.0)$ & $126(100.0)$ & $100(100.0)$ & $197(100.0)$ & $297(100.0)$ \\
\hline
\end{tabular}

\section{Discussion}

The most significant finding from this study is that communities are aware that the African wild dog is a threatened species that requires a high conservation priority. Furthermore, to capture and relocate wild dogs was considered to be a negative approach by the Maasai tribe, indicating that the wild dog has a potential value through tourism within the LGCA. However, there was a difference in opinion about the relocation of wild dogs from the LGCA to the SNP, as there was a positive response to releasing wild dogs to the park, as it was regarded to be important for the species' conservation and tourism development.

\subsection{Conservation Perceptions under the IUCN Categories}

In our study, more females than males regarded wild dogs as extinct, most likely because females are more engaged with home activities in the pastoral community, which limits their movement over long distances (Nelson \& Makko, 2005). This may reduce their probability of coming into contact with wild dogs and hence limits their understanding of the species' presence in their area (see also Mmassy \& Røskaft, 2013). Abram et al. (2015) reported that local knowledge on endangered species should be incorporated in species conservation plans and management. Thus, indigenous communities' knowledge of biological diversity conservation has been suggested as a key component for a successful management of a species (Abram et al., 2015; Iftekhar \& Takama, 2008; Lindsey et al., 2005; Liu et al., 2011). Conservation of endangered species inhabiting community land is largely dependent on local people's knowledge and perception of the species, as this in turn influences their behaviour. The local people's perception on species management have been reported in several studies (Inskip et al., 2016; Liu et al., 2011; Lyamuya et al., 2014; Schuette et al., 2013; Zimmermann et al., 2010).

In general, the majority of respondents from the Sonjo tribe mentioned that the wild dogs are extinct, which could be due to the fact that most species of large carnivores are absent in this area. However, human settlement is much more developed in the Sonjo area compared to areas where the Maasai tribe live, which may also affect the presence of wild dogs in this area. Thus our finding is in support with our prediction that local knowledge on species under IUCN categories differ between gender and tribe (or location). Increased human settlement cause species extinctions and reduces interactions with people (Harihar, Ghosh-Harihar, \& MacMillan, 2014; Inskip et al., 2016; Trouwborst, 2015). In contrast, IUCN categories of a species conservation status is solely based on the distribution of a species in a geographical location.

\subsection{Conservation Priorities}

Fewer Maasai than Sonjo people considered the wild dog to have a low conservation priority, supporting the previously described high knowledge level of the Maasai tribe. The Sonjo people, on the other hand, suggested that wild dog conservation should be of high priority, as it is the only large carnivore remaining within their vicinity. Successful management of large carnivores is an important issue for conservation biologists. Previous studies suggested that local knowledge is a powerful tool for conveying conservation information to managers (Kideghesho, 2008; Ray, Hunter, \& Zigouris, 2005). Indigenous knowledge of birds in our study area has been reported to be quite high among the Maasai people (Mmassy \& Røskaft, 2013). Thus, the Maasai people have previously proven to be quite knowledgeable about ability to know different wild animal species.

Educated people recommended a high conservation priority of wild dogs. The majority of the local people have attained formal education and has the ability to exchange conservation knowledge among themselves. Similarly, relationship between education level and conservation priority attitudes towards large carnivores has been reported previously (Bhatia, Redpath, Suryawanshi, \& Mishra, 2016; Carter, Riley, \& Liu, 2012; Lagendijk \& Gusset, 2008; Lindsey et al., 2005; Parker et al., 2014; Røskaft et al., 2007). The educated respondents have the possibility to watch television, read newspapers and books which might also be important means of obtaining 
information regarding wild dogs, which again increases the awareness of local people about wild dog conservation priorities. Finding from our study is that the suggested high conservation priority is due to the fact that wild dogs sightings are uncommon within the area. People may acquire biological information about the species so as to develop good protection of their property during predation periods (Karlsson \& Sjöström, 2011; Trouwborst, 2015). However, our results support the hypothesis that the Maasai tribe assigns a higher priority to wild dog conservation than the Sonjo tribe.

\subsection{Perceptions on Capturing and Releasing Wild Dogs}

In Maasai areas, local people opposed the idea of capturing wild dogs and suggested that it is bad for conservation of the species. The reason for this might be that Maasai people reside in areas with a high carnivore density and therefore receive direct benefits from wildlife utilization. In addition, knowledge of wild dog conservation is widespread among the Maasai people. This may be attributed to the formal system of conveying information within the traditional living societies. Translocation involves capturing; exposing animals to human care, stress, transport, and potential injuries; and releasing animals into a new area (Athreya, Odden, Linnell, \& Karanth, 2011; Davies-Mostert et al., 2015; Gusset et al., 2008), this is similar to our findings. However, translocation might have both positive and negative consequences (Athreya et al., 2011; Gusset et al., 2008).

In our case, female respondents were more positive to relocating wild dogs to SNP than were males. As previously reported, gender plays an important role in the perception of conservation of wild canids (Bhatia et al., 2016; Carter et al., 2012; Lindsey et al., 2005; Liu et al., 2011; Treves \& Karanth, 2003). However, the presence of wild dogs in the areas has limited benefits to local people, which may contribute to the positive suggestions of relocating the dogs to the park. It is likely that opinion differences by gender within the tribe regarding wild dog release is influenced by culture. In this case, the Maasai tribe has a stronger positive cultural norm in terms of wildlife conservation compared to the Sonjo tribe.

On the other hand, the Maasai tribe was more in favour of the idea of releasing wild dogs into SNP, as they are aware that wild dogs are important to tourists. The access of tourists to Maasai-dominated areas has increased wild dog conservation awareness. The presence of tourist facilities and game rangers may have led to an increase in the protection status of wild dogs in the park. Although the pastoral community dislikes co-existing with large carnivores (Berger, 2007; Majić, Marino Taussig de Bodonia, Huber, \& Bunnefeld, 2011; Parker et al., 2014; Valeix et al., 2012), the positive suggestions from our respondents to releasing wild dogs into SNP indicate that the wild dog population will perform better by being translocated in the park due to a reduction of wild dog killing after their livestock. Simultaneously, removing wild dogs from the LGCA may improve the economic well-being of the local pastoralists through the reduction of depredation incidences. Therefore our result is in support with our hypothesis that tribe was a strong predictor of human perceptions of wild dog capture and release.

\section{Conclusion and Recommendations}

From the current study, gender, tribe and education level were important independent variables explaining people's opinions towards African wild dog conservation in the LGCA. These differences may be important to consider and integrate into conservation strategies for African wild dogs by the management authorities within the Serengeti ecosystem and other areas in Tanzania.

\section{Acknowledgements}

We are grateful to local communities in LGCA for participating in the survey. We further thank Tanzania Wildlife Research Institute (TAWIRI) for approving the research. This study was funded by a grant from the Ministry of Foreign Affairs in Norway through the Environmental Agency of Norway to the Norwegian University of Science and Technology (NTNU) at the Department of Biology, and Tanzania Wildlife Research Institute (TAWIRI). The project is a capacity building project under Intergovernmental Policy Platform on Biodiversity \& Ecosystem Services (IPBES) as a part of the project titled "The dynamics of large infrastructure development in conservation of the Serengeti Ecosystem - the case study of a road through Serengeti National Park". In addition Vodacom T. Ltd, Tanzania National Parks, BIOTOPE T. LTD, Ngorongoro Conservation Area and Norwegian University of Science and Technology (NTNU) provided some funding to this study.

\section{References}

Abram, N. K., Meijaard, E., Wells, J. A., Ancrenaz, M., Pellier, A. S., Runting, R. K., Nurcahyo, A. (2015). Mapping perceptions of species' threats and population trends to inform conservation efforts: the Bornean orangutan case study. Diversity and Distributions, 21(5), 487-499. http://dx.doi.org/10.1111/ddi.12286

Andy, F. (2009). Discovery Statistics Using SPSS London.: Sage Publication Ltd. 
Athreya, V., Odden, M., Linnell, J. D., \& Karanth, K. U. (2011). Translocation as a tool for mitigating conflict with leopards in human-dominated landscapes of India. Conservation Biology, 25(1), 133-141. http://dx.doi.org/http://dx.doi.org/10.1111/j.1523-1739.2010.01599.x

Berger, J. (2007). Fear, human shields and the redistribution of prey and predators in protected areas. Biology Letters, 3(6), 620-623. http://dx.doi.org/10.1098/rsbl.2007.0415.

Bhatia, S., Redpath, S. M., Suryawanshi, K., \& Mishra, C. (2016). The Relationship Between Religion and Attitudes Toward Large Carnivores in Northern India? Human Dimensions of Wildlife, 1-13. http://dx.doi.org/10.1080/10871209.2016.1220034

Carter, N. H., Riley, S. J., \& Liu, J. (2012). Utility of a psychological framework for carnivore conservation. Oryx, 46(04), 525-535. http://dx.doi.org/10.1017/S0030605312000245.

Davies-Mostert, H. T., Mills, M. G., \& Macdonald, D. W. (2015). The demography and dynamics of an expanding, managed African wild dog metapopulation. South African Journal of Wildlife Research, 45(2), 258-273. http://dx.doi.org/10.3957/056.045.0258

Dickman, A. J., Macdonald, E. A., \& Macdonald, D. W. (2011 ). A review of financial instruments to pay for predator conservation and encourage human-carnivore coexistence. Proceedings of the National Academy of Sciences of the United States of America, 108(34), 13937-13944. http://dx.doi.org/10.1073/pnas.1012972108

Ghosal, S., Skogen, K., \& Krishnan, S. (2015). Locating human-wildlife interactions: Landscape constructions and responses to large carnivore conservation in India and Norway. Conservation and Society, 13(3), 265. http://dx.doi.org/10.4103/0972-4923.170403

Gusset, M., Ryan, S. J., Hofmeyr, M., Van Dyk, G., Davies-Mostert, H. T., Graf, J. A., . . . Monfort, S. L. (2008). Efforts going to the dogs? Evaluating attempts to re-introduce endangered wild dogs in South Africa. Journal of Applied Ecology, 45(1), 100-108. http://dx.doi.org/10.1111/j.1365-2664.2007.01357.x

Harihar, A., Ghosh-Harihar, M., \& MacMillan, D. C. (2014). Human resettlement and tiger conservation-socio-economic assessment of pastoralists reveals a rare conservation opportunity in a human-dominated landscape. Biological Conservation, 169, 167-175. http://dx.doi.org/10.1016/j.biocon. 2013.11.012

Homewood, K., Lambin, E. T., Coast, E., Kariuki, A., Kikula, I., Kivelia, J., . . Thompson, M. (2001). Long-term changes in Serengeti-Mara wildebeest and land cover: pastoralism, population, or policies? Paper presented at the PNAS.http://dx.doi.org/10.1073/pnas.221053998

Howe, E. J., Obbard, M. E., Black, R., \& Wall, L. L. (2010). Do public complaints reflect trends in human-bear conflict? Ursus, 21(2), 131-142. http://dx.doi.org/10.2192/09GR013.1

Iftekhar, M., \& Takama, T. (2008). Perceptions of biodiversity, environmental services, and conservation of planted mangroves: a case study on Nijhum Dwip Island, Bangladesh. Wetlands Ecology and Management, 16(2), 119-137. http://dx.doi.org/10.1007/s11273-007-9060-8

Inskip, C., Carter, N., Riley, S., Roberts, T., \& MacMillan, D. (2016). Toward Human-Carnivore Coexistence: Understanding Tolerance for Tigers in Bangladesh. PloSone, 11(1), http://dx.doi.org/10.1371/journal.pone. 0145913

Johansson, M., \& Frank, J. (2016). The impact of access to an ultrasonic scaring device on human fear of wolves. Wildlife Biology, 22, 29-36. http://dx.doi.org/10.2981/wlb.00154

Karlsson, J., \& Sjöström, M. (2011). Subsidized fencing of livestock as a means of increasing tolerance for wolves. Ecology and Society, 16(1), 16. Retrieved from http://www.ecologyandsociety.org/voll6/iss1/art16

Kideghesho, J. R. (2008). Co-existence between the traditional societies and wildlife in western Serengeti, Tanzania: its relevancy in contemporary wildlife conservation efforts. Biodiversity and Conservation, 17(8), 1861-1881. http://dx.doi.org/10.1007/s10531-007-9306-z

Lagendijk, D. G., \& Gusset, M. (2008). Human-carnivore coexistence on communal land bordering the Greater Kruger Area, South Africa. Environmental Management, 42(6), 971-976.http://dx.doi.org/10.1007/s00267 $-008-9204-5$

Lindsey, P. A., Du Toit, J. T., \& Mills, M. (2005). Attitudes of ranchers towards African wild dogs (Lycaon pictus): Conservation implications on private land. Biological Conservation, 125(1), 113-121. http://dx.doi.org/10.1016/j.biocon.2005.03.015 
Lindsey, P. A., Havemann, C. P., Lines, R., Palazy, L., Price, A. E., Retief, T. A., . . Van der Waal, C. (2013). Determinants of Persistence and Tolerance of Carnivores on Namibian Ranches: Implications for Conservation on Southern African Private Lands. PlosOne, 8(1). http://dx.doi.org/10.1371/journal.pone. 0052458

Linnell, J. D., Swenson, J. E., \& Anderson, R. (2001). Predators and people: conservation of large carnivores is possible at high human densities if management policy is favourable. Animal Conservation, 4(4), 345-349. http://dx.doi.org/10.1017/S1367943001001408

Liu, F., McShea, W. J., Garshelis, D. L., Zhu, X., Wang, D., \& Shao, L. (2011). Human-wildlife conflicts influence attitudes but not necessarily behaviors: factors driving the poaching of bears in China. Biological Conservation, 144(1), 538-547. http://dx.doi.org/10.1016/j.biocon.2010.10.009

Løe, J., \& Røskaft, E. (2004). Large carnivores and human safety: A review. Ambio, 33(6), 283-288. http://dx.doi.org/10.1579/0044-7447-33.6.283

Lyamuya, R., Masenga, E., Fyumagwa, R., \& Røskaft, E. (2014). Human-carnivore conflict over livestock in the eastern part of the Serengeti ecosystem, with a particular focus on the African wild dog Lycaon pictus. Oryx, 48(03), 378-384. http://dx.doi.org/10.1017/S0030605312001706

Lyamuya, R., Masenga, E., Mbise, F., Fyumagwa, D., Mwita, M., \& Røskaft, E. (2014). Attitudes of maasai pastoralists towards conservation of large carnivores in the Loliondo Game Controlled Area , Tanzania. International Journal of Biodiversity and Conservataion, 6, 797-805. http://dx.doi.org/10.5897/IJBC2014.0769

Majić, A., Marino Taussig de Bodonia, A., Huber, Đ., \& Bunnefeld, N. (2011). Dynamics of public attitudes toward bears and the role of bear hunting in Croatia. Biological Conservation, 144(12), 3018-3027. http://dx.doi.org/10.1016/j.biocon.2011.09.005

Masenga, E. (2011). Abundance, distribution and conservation threats of African wild dog (Lycaon pictus) in the Loliondo Game Controlled Area, Tanzania. (MSc. thesis. ), Sokoine University of Agriculture, Morogoro, Tanzania.

Masenga, E., Lyamuya, R., Nyaki, A., Kuya, S., Jaco, A., Kohi, E., . . Røskaft, E. (2013). Strychnine poisoning in African wild dogs (Lycaon pictus) in the Loliondo game controlled area, Tanzania. International Journal of Biodiversirsety Conservatiob 5, 367-370. http://dx.doi.org/10.5897/IJBC12.100

Mmassy, E. C., \& Røskaft, E. (2013). Knowledge of birds of conservation interest among the people living close to protected areas in Serengeti, Northern Tanzania. International Journal of Biodiversity Science, Ecosystem Services \& Management, 9(2), 114-122. http://dx.doi.org/10.1080/21513732.2013.788566

NBS. (2012). Population and housing cencus. Population distribution by admistrative areas. Retrieved from Ministry of Ministry of Finance Dar es salaam and President's office, Economy and development planning Zanzibar.

Nelson, F., \& Makko, S. O. (2005). Communities, conservation, and conflicts in the Tanzanian Serengeti. Third annual community-based conservation network seminar: turning natural resources into assets, Savannah Georgia, forthcoming.

Packer, C., Loveridge, A., Canney, S., Caro, T., Garnett, S., Pfeifer, M., ... Balme, G. (2013). Conserving large carnivores: dollars and fence. Ecology letters, 16(5), 635-641. http://dx.doi.org/10.1111/ele.12091

Pan, R., Oxnard, C., Grueter, C. C., Li, B., Qi, X., He, G., ... Garber, P. A. (2016). A new conservation strategy for China-A model starting with primates. American Journal of Primatology. http://dx.doi.org/10. 1002/ajp.22577

Parker, D. M., Whittington-Jones, B. M., Bernard, R. T., \& Davies-Mostert, H. T. (2014). Attitudes of rural communities toward dispersing African wild dogs in South Africa. Human Dimensions of Wildlife, 19(6), 512-522. http://dx.doi.org/10.1080/10871209.2014.926575

Ray, J. C., Hunter, L., \& Zigouris, J. (2005). Setting conservation and research priorities for larger African carnivores (Vol. 24): Wildlife Conservation Society New York.

Røskaft, E., Bjerke, T., Kaltenborn, B., Linnell, J. D., \& Andersen, R. (2003). Patterns of self-reported fear towards large carnivores among the Norwegian public. Evolution and Human Behavior, 24(3), 184-198. http://dx.doi.org/10.1016/S1090-5138(03)00011-4 
Røskaft, E., Händel, B., Bjerke, T., \& Kaltenborn, B. P. (2007). Human attitudes towards large carnivores in Norway. Wildlife Biology, 13(2), 172-185. http://dx.doi.org/10.2981/0909-6396(2007)13[172:HATLCI]2.0. $\mathrm{CO} ; 2$

Schuette, P., Creel, S., \& Christianson, D. (2013). Coexistence of African lions, livestock, and people in a landscape with variable human land use and seasonal movements. Biological Conservation, 157, 148-154. http://dx.doi.org/10.1016/j.biocon.2012.09.011

Stein, A., Fuller, T., Damery, D., Sievert, L., \& Marker, L. (2010). Farm management and economic analyses of leopard conservation in north-central Namibia. Animal Conservation, 13(4), 419-427. http://dx.doi.org/10. $1111 / \mathrm{j} .1469-1795.2010 .00364 . \mathrm{x}$

TAWIRI. (2009). Tanzania Carnivore Conservation Action Plan. Tanzania Wildlife Reserach Institute. Arusha, Tanzania. 142.

Treves, A., \& Karanth, K. U. (2003). Human-carnivore conflict and perspectives on carnivore management worldwide. Conservation Biology, 17(6), 1491-1499. http://dx.doi.org/10.1111/j.1523-1739.2003.00059.x

Trouwborst, A. (2015). Global large carnivore conservation and international law. Biodiversity and Conservation, 24(7), 1567-1588.

Tumbo, S., Mutabazi, K., Kimambo, A., \& Rwehumbiza, F. (2011). Costing and planning of adaptation to climate change in animal agriculture in Tanzania: IIED, London.

Valeix, M., Hemson, G., Loveridge, A. J., Mills, G., \& Macdonald, D. W. (2012). Behavioural adjustments of a large carnivore to access secondary prey in a human-dominated landscape. Journal of Applied Ecology, 49(1), 73-81. http://dx.doi.org/10.1111/j.1365-2664.2011.02099.x

Weise, F. J., Stratford, K. J., \& van Vuuren, R. J. (2014). Financial Costs of Large Carnivore Translocations-Accounting for Conservation. PloSone, 9(8), http://dx.doi.org/10.1371/journal.pone.0105 042

Woodroffe, R. (2000). Predators and people: using human densities to interpret declines of large carnivores Animal Conservation, 3, 165-173. http://dx.doi.org/S136794300000086X

Woodroffe, R. (2011). Ranging behaviour of African wild dog packs in a human-dominated landscape. Journal of Zoology, 283(2), 88-97. http://dx.doi.org/10.1111/j.1469-7998.2010.00747.x

Woodroffe, R., Lindsey, P., Romanach, S., Stein, A., \& ole Ranah, S. M. (2005). Livestock predation by endangered African wild dogs (Lycaon pictus) in northern Kenya. Biological Conservation, 124(2), 225-234. http://dx.doi.org/10.1016/j.biocon.2005.01.028

Zimmermann, A., Baker, N., Inskip, C., Linnell, J. D., Marchini, S., Odden, J., . . . Treves, A. (2010). Contemporary views of human-carnivore conflicts on wild rangelands. In J. T. du Toit, R. Kock, \& J. C. Deutsch (Eds.), Wild Rangelands: Conserving wildlife while maintaining livestock in semi-arid ecosystems (pp. 129-151). New York: Blackwell.

\section{Copyrights}

Copyright for this article is retained by the author(s), with first publication rights granted to the journal.

This is an open-access article distributed under the terms and conditions of the Creative Commons Attribution license (http://creativecommons.org/licenses/by/4.0/). 